\title{
Finite element modeling of concrete confined with circular thin-walled steel sheet
}

\author{
Ashando Hario Yudhanto ${ }^{1}$, Bambang Piscesa ${ }^{1 *}$, Mario M. Attard ${ }^{2}$, Budi Suswanto ${ }^{1}$, Priyo Suprobo ${ }^{1}$ \\ ${ }^{1}$ Civil Engineering Department, Institut Teknologi Sepuluh Nopember, 60111 Surabaya, Indonesia \\ ${ }^{2}$ School of Civil and Environmental Engineering, the University of New South Wales, NSW 2052, Sydney, Australia
}

\begin{abstract}
For a reinforced concrete column to behave in a ductile manner without much loss on strength requires sufficient confinement to the concrete core. One way to provide confinement to the concrete core is to use external confining devices such as a series of thin-walled circular steel sheet tube to confine the concrete. This type of external confining device falls off on the categories of Steel Tube Confined Concrete (STCC). With the presence of a gap between the steel sheet, the buckling on the tube due to high axial stresses can be avoided. On the other hand, STCC also offers great advantages to strengthen a non-code conforming reinforced concrete column to achieve better resistance to withstand earthquake load. From the numerical analysis point of view, the important task to successfully model the STCC specimen lies in the modeling of the interface behavior between concrete and steel tube. For that purpose, in this paper, the 3D-NLFEA package is used to study the response of STCC. The analysis result is further compared with the available test results in the literature. From the analysis, the predicted response is excellent. Detailed discussion on the parameter of the interface behavior between concrete and steel tube is presented.
\end{abstract}

\section{Introduction}

With the rapid research development of seismic risk in Indonesia, there is a need to evaluate existing structures to conform to the new design regulations. For existing structures that are not code-compliance, several options can be sought. Among those options, strengthening the structures was almost always considered as the best option. In most cases, the member that heavily loaded in axial compression (such as Reinforced Concrete (RC) column) would be one of the most important structural elements to be strengthened. Although there were many ways to strengthen the RC column, in this paper, the attention is focused on the external strengthening using a series of thin-walled circular steel sheet tube confined concrete which also well known as Steel Tube Confined Concrete (STCC). From the study carried out by [1], STCC can have excellent earthquake resistance, high ductility, and large energy absorption capacity.

STCC was firstly introduced by Tomii [2]. According to Tomii [2], STCC is not connected to the beam and can only restraint the concrete in the lateral direction. It does increase the concrete core strength and ductility but weak in the disconnection region. Hence, longitudinal reinforcing bars are required to carry the bending moment and enhanced the bending stiffness of the column [1].

STCC can be easily used to strengthen the RC column despite its size and cross-sectional shapes. For a column with a non-circular dimension, additional concrete jacketing can be used before the application of STCC. By using STCC, there is a possibility to upgrade the level of structural category either from ordinary to intermediate or from intermediate to special moment-resisting frames. Moreover, the cover spalling problem can be avoided by using STCC [1]. However, STCC should be protected against fire to avoid the loss of strength and ductility of the column.

Le Hoang and Fehling [3] studied the behavior of the STCC column using ATENA-3D package. In [3], the STCC specimen modeled had a full height between the disconnected region. On the other hand, the STCC specimen investigated in this paper consisted of a steel tube element with a gap. This gap will prevent the occurrence of local buckling on the tube and reduces the axial stress development on the tube during loading. In this paper, the numerical simulation uses the 3D-NLFEA package which was developed by Piscesa [4], [5, 6] which also incorporates the plasticity-fracture model as in ATENA-3D but with more enhanced confinement plasticity model with non-constant plastic dilation rate and confinement restraint sensitive model.

\section{Finite Element Package ATENA-3D [3] and 3D-NLFEA [4-6]}

In the study of [3], the solid element was modeled using a tetrahedral element with reduced integration (four Gauss points). It was not clear if anti-hour glassing formulation was used. The maximum mesh size was set to $30 \mathrm{~mm}$. The interface behavior was modeled using the zero thickness interface element. The concrete constitutive model for compression was based on the model proposed by

corresponding authors : piscesa@ce.its.ac.id 
Papanikolaou and Kappos [7] with modification on both the hardening and the softening function. In [3], the softening behavior was based on the axial displacement acting on a band length for compression. The purpose was to induce a size effect during compression once localization takes place.

However, this authors thought that the axial displacement should be related to the sliding of the shear plane during compression plus the tensile splitting cracking [8, 9] rather than relying only on axial deformation. The constitutive model for the interface element was based on the Mohr-Coulomb plasticity model with softening. Furthermore, it was not clear on the detail parameter for the plastic potential function used in the simulation. The steel tube constitutive model follows the Mises criterion with elastic-perfectly plastic model for some specimen and for the other specimen with the elastic-plastic model with linear hardening.

In this paper, the 3D-NLFEA package is used for numerical simulation. The element is modeled using eight-node hexahedral element with selective integration (BBar) element to avoid volumetric locking [10]. The maximum mesh size is set to $10 \mathrm{~mm}$. The concrete constitutive model for compression was based on the model of Piscesa, et al. [11]. In [11], the Menetrey and Willam [12] failure surface was modified to include the frictional driver parameter which will enhance the prediction of both the peak and residual stresses of the model.

The lateral strain model follows the model of Piscesa, et al. [13] which can incorporate initial plastic volumetric compaction, plastic volumetric compaction due to pore collapses, and the ability to switch from passive confinement state to active confinement state via the lateral modulus parameter. By using this lateral modulus parameter, the effectiveness of the external confining device before and after yielding can be monitored throughout the loading step. 3D-NLFEA has been used to simulate RC confined with carbon fiber wrap [6, 14], cover spalling analysis in high- and very high-strength RC column [5], and concrete-filled steel tube under eccentric and concentric loading $[15,16]$.

The steel tube constitutive model follows the Mises criterion with an elastic-perfectly plastic model. Von Mises yield criterion has been adopted to define the yield point of the steel [17]. The element used to model the steel tube is the eight-noded hexahedral element with BBar element technology. The interface element was modeled using a zero thickness element [18] and follows the MohrCoulomb plasticity model with a non-associative flow rule. The returned mapping used for the interface element uses the Tangent Cutting Plane (TCP) proposed by Ortiz and Simo [19]. The expression of the Mohr-Coulomb plasticity model is:

$$
f=\tau_{1}^{n}+\tau_{2}^{n}-\left(c-\sigma_{\mathrm{n}} \tan \phi\right)^{n}+(c-\xi \tan \phi)^{n}
$$

In Eqn.(1), $\tau_{1}$ is the shear stress in the principal 1 direction, $\tau_{2}$ is the shear stress in the principal 2 direction, $c$ is the cohesive shear strength at the onset of slip occurrence, $\phi$ is the friction angle which relates the roughness surface between the concrete and steel tube, $\bullet$ is the bonding strength between the concrete and steel tube, $\mathrm{n}$ is the number that controls the elliptical curve in the tension region (the standard value is two but in this paper, the value of $\mathrm{n}$ is set to four). There is no softening once the slip occurred.

In [3], the full Newton-Raphson iteration method is used to solve the nonlinear iteration. In 3D-NLFEA, Initial Stiffness Method (ISM) with Tangent Stiffness Like Projection Method (TSLPM, see [4]) is used. To further speed up the convergence, Process Modification [20] with maximum of two stages modification is used. In the simulation, there are no random material and geometric imperfection used. The $2^{\text {nd }}$ order analysis in 3D-NLFEA is turned off.

\section{3D Modeling of STCC Specimen}

To model the STCC specimen in $3 \mathrm{D}$, the SALOME platform [21] was used as the preprocessor. One STCC specimen (STCC_1) with a gap from [1] is selected for simulation. The STCC_1 specimen concrete strength is 62.7 $\mathrm{MPa}$. The concrete specimen diameter is $200 \mathrm{~mm}$. The steel tube thickness is $1.945 \mathrm{~mm}$. The total height of the specimen is $600 \mathrm{~mm}$. The height of one steel tube is $120 \mathrm{~mm}$. The yield strength of the tube is $277 \mathrm{MPa}$. Fig. 1 shows the specimen's side view and its cross section.

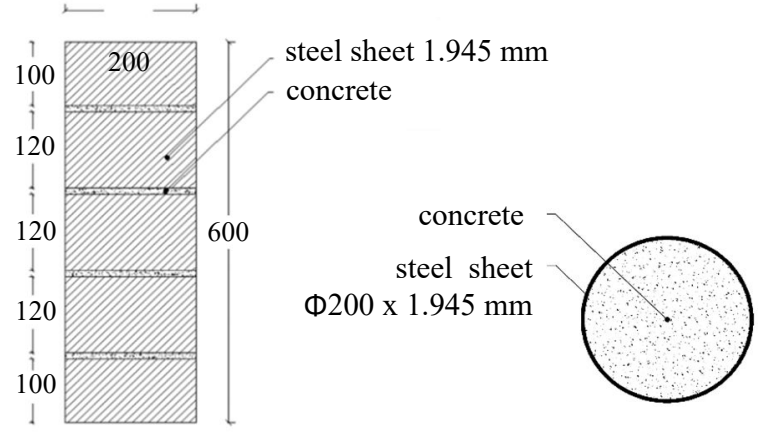

Fig. 1 Side view and cross section

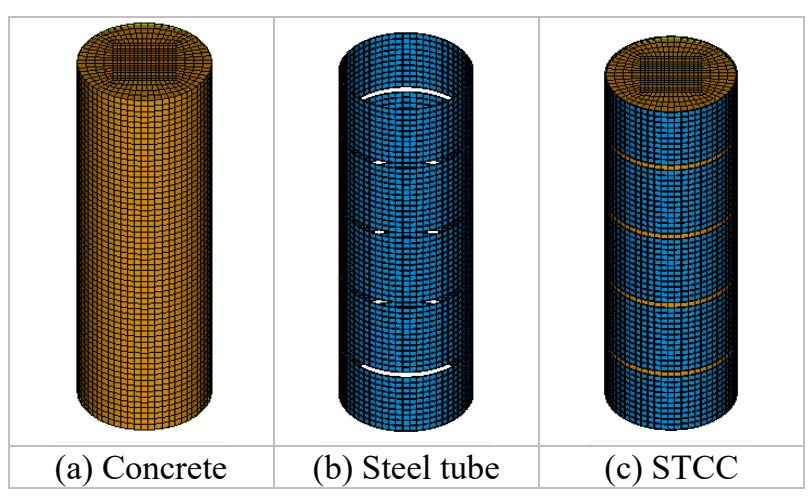

Fig. 2 STCC_1 specimen meshed model in SALOME 
Fig.2 shows the meshed model of the STCC_1 specimen. The total number of elements is 31,260 . The total number of nodes is 33,916 . The load is controlled using displacement at the top end. The bottom end is fixed in all directions while the top end is only fixed in the lateral direction. The displacement increment for each time step is set to $-0.01 \mathrm{~mm}$.

\section{Comparison with Experimental Result}

One STCC specimen tested by Liu, et al. [1] is used here for comparison purposes with the analysis results from 3D-NLFEA. Fig. 3 shows the axial load of the STCC specimen which agrees well with the test result. It should be noted that the load-deflection curve from the analysis shown in Fig. 3 was generated using the parameter value for the zero thickness element such as the cohesive shear strength is set to $2.75 \mathrm{MPa}$, the friction angle is set to $45^{\circ}$ and the uniaxial tensile stress limit is set to the minimum between $5 \mathrm{MPa}$ or $c / \tan \phi$.

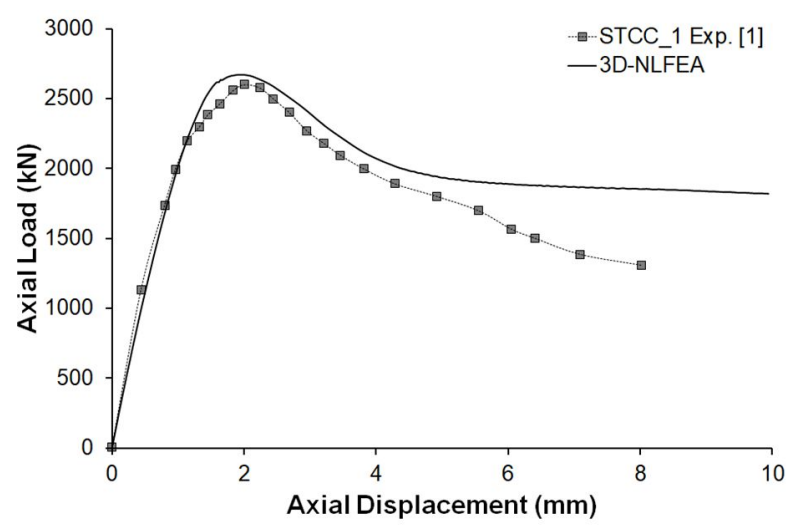

Fig. 3 Axial load versus displacement relationship

\section{Stress Analysis on The Steel Tube}

Fig. 4 shows the typical stresses which act on the steel tube. As shown in Fig.4, there were mainly four stresses which play an important role to understand the behavior of steel tube on the STCC specimen. These stresses were the hoop stress or the transverse stress $\left(\sigma_{\mathrm{st}}\right)$, the axial stress $\left(\sigma_{\mathrm{sl}}\right)$, and the lateral stress $\left(f_{1}\right)$ which was equivalent to the confining pressure to the concrete core, and shear friction stress $(f)$ which transfer via the skin-friction between the concrete and the steel tube. Since there is a presence of this shear friction stress, it was expected that the distribution of the axial stress on the tube was not uniform along with the height of the STCC specimen. At the start of the disconnected region, the axial stress of the tube is at the minimum and gradually increases as it goes away from the disconnected region. The maximum axial stress on the tube was found to be at the mid-height of each tube.

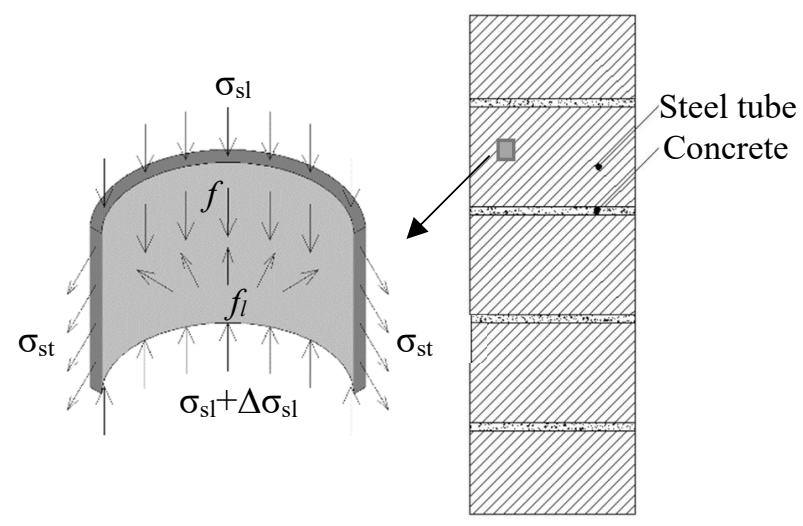

Fig. 4 Stresses on the steel tube

Fig.5 shows the axial stress or longitudinal stress acting on the tube (at peak load) which confirms the theory of this skin-friction effect between concrete and steel tube. From the analysis, the axial load for each steel tube varies and the tube at mid-height section provides lesser axial stress at its mid-height section which could be attributed to higher confining pressure at the mid-height section of the specimen.
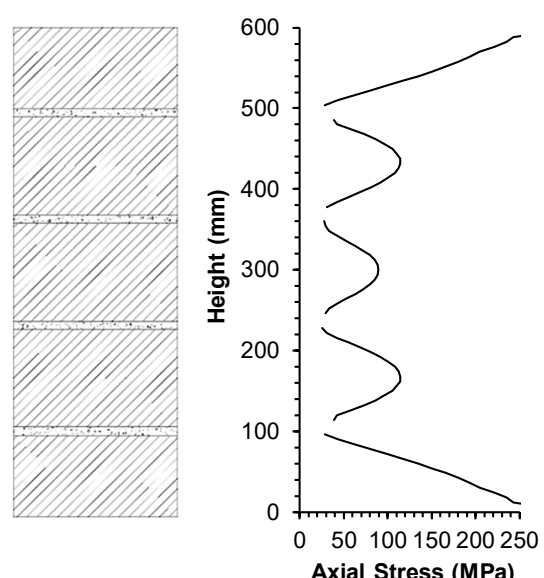

Fig. 5 Axial or longitudinal stress acting on the steel tube
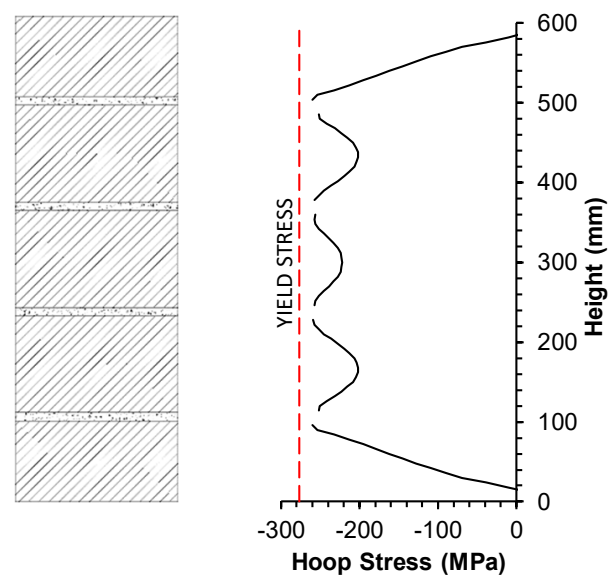

Fig. 6 Hoop or transverse stress acting on the steel tube 
Fig.6 shows the hoop or transverse stress acting on the steel tube. The red dashed line in Fig. 6 shows the yield limit of the steel tube if loaded in uniaxial direction (either in compression or tension). As shown in Fig.6, the hoop stress on the steel tube reaches its maximum value when the axial stress on the steel tube is at minimum which is at the start of the disconnected region. The hoop stress reduces as it goes to the mid-height section of the tube which can be attributed to the increase in the axial stress on tube. The minimum hoop stress was found at the midheight section of the tube.

\section{Sensitivity Analysis of The Interface Element Constitutive Model}

In this section, sensitivity analysis of the interface element constitutive model is presented. In addition to the sensitivity analysis, a perfect bond model for the interaction between the concrete and the tube is also presented for comparison purposes. Fig.8a and Fig.8b show the comparison of the axial and hoop stresses distribution acting on the tube between the experimental test and numerical analysis with perfect bond assumption, respectively. As shown in Fig.8a, the peak axial stress was well compared with the test result. However, the occurrence of the peak axial stress differs significantly between the numerical model and the test result.

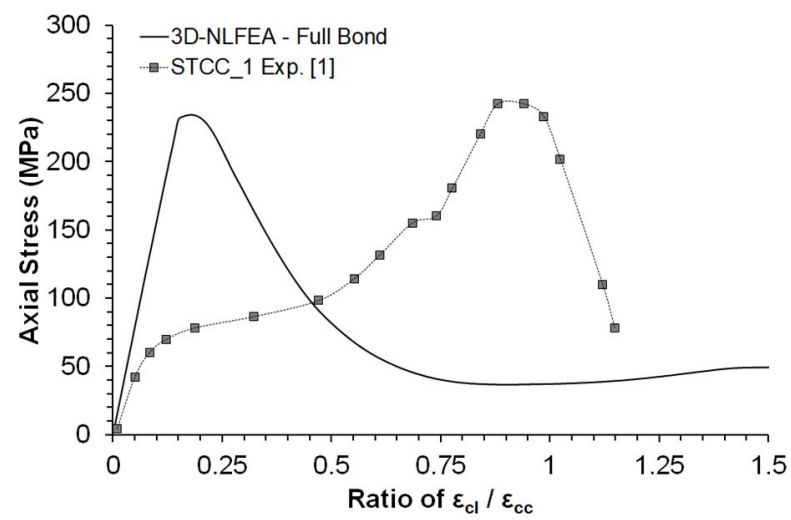

(a) Axial stress on the steel tube vs ratio of $\varepsilon_{\mathrm{cl}} / \varepsilon_{\mathrm{cc}}$

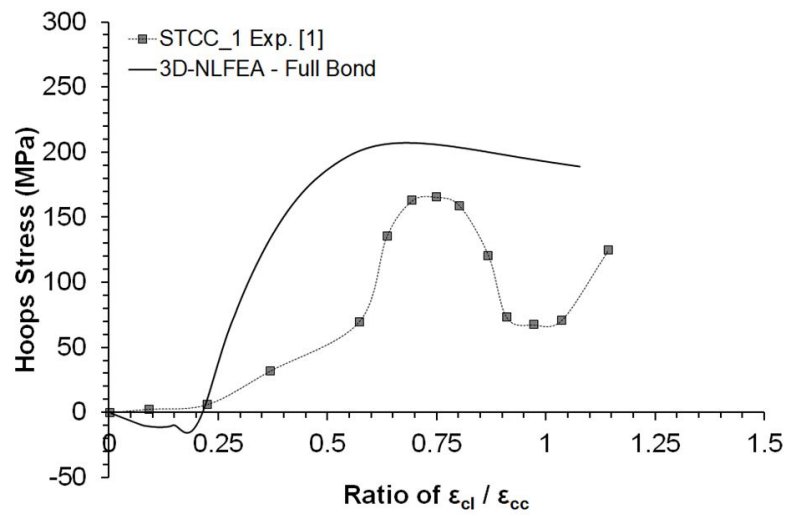

(b) Hoop stress on the steel tube vs ratio of $\varepsilon_{\mathrm{cl}} / \varepsilon_{\mathrm{cc}}$

Fig. 8 Stresses behavior on the steel tube using full bond assumption between concrete and the steel tube
In the test result, the slip occurs and the growth of axial stress on the tube was significantly reduced until the lateral pressure exerted by the concrete kicks in. Once the lateral pressure generated was large enough, the shear stress on the interface increases which eventually increases the axial stress on the tube. From Fig. 8 b, there is no negative hoop stress observed from the test result. However, in numerical simulation with perfect bond, the initial hoop stress was found to be negative. This can be well understood due to the Poisson's ratio of the concrete is smaller than the steel tube. Once axially loaded, the expansion of concrete is smaller than the steel tube. Hence, the concrete pulls the steel tube inward and generates negative hoop stress if the perfect bond assumption between the concrete and the steel tube interface is used. However, once the concrete cracks and total Poisson's ratio (elastic plus the plastic dilation rate) of the concrete is greater than the Poisson's ratio of the steel tube, the hoop stress changes from negative to positive.

As for the sensitivity analysis, variation on the friction angle, cohesive shear strength, and bond uniaxial tensile strength are presented. For the variations on the friction angle, the observed values are 35, 45 and 55 degrees. For the variations on the cohesive shear strength, the observed values are $2.25,2.75$ and $3.25 \mathrm{MPa}$. For the variations on the bond uniaxial tensile strength, the observed values are 2 and $5 \mathrm{MPa}$ but not greater than $c / \tan \phi$.

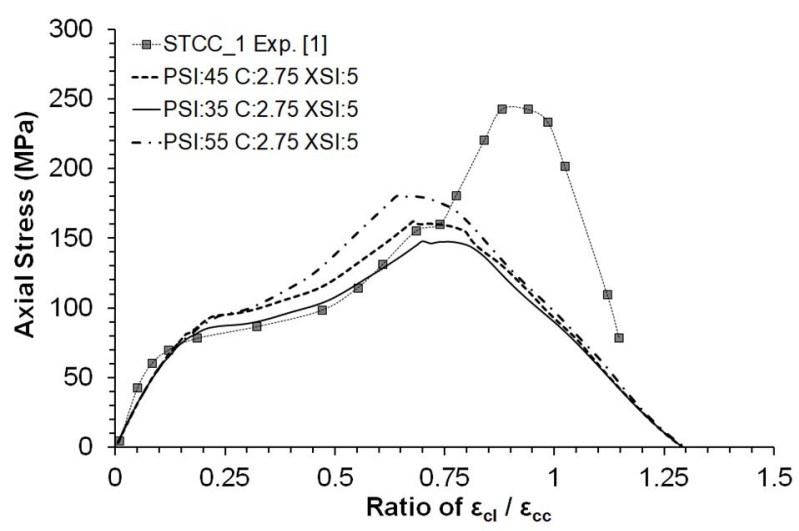

(a) Axial stress on the steel tube vs ratio of $\varepsilon_{\mathrm{cl}} / \varepsilon_{\mathrm{cc}}$

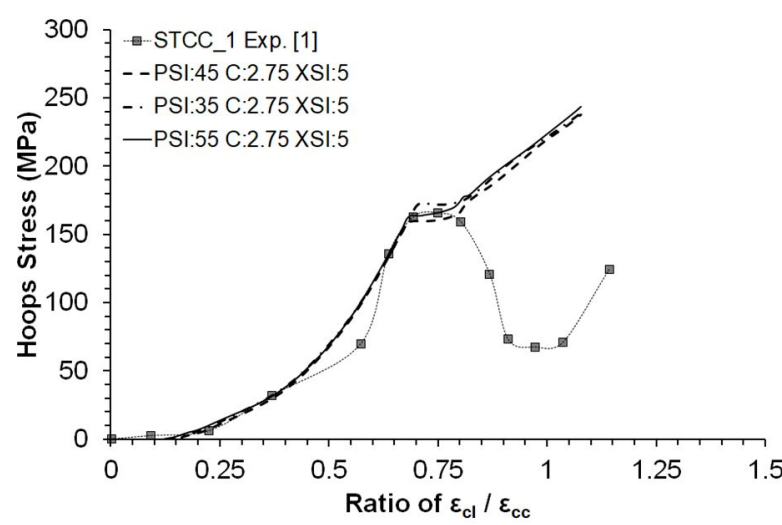

(b) Hoop stress on the steel tube vs ratio of $\varepsilon_{\mathrm{cl}} / \varepsilon_{\mathrm{cc}}$

Fig. 9 Stresses behavior on the steel tube with varying friction angle values 
Fig.9a and Fig.9b show the comparison of the axial and hoop stresses distribution acting on the tube between the experimental test and numerical analysis with varying friction angle values, respectively. The values for the cohesion are set to $2.75 \mathrm{MPa}$ and the initial bond tensile strength is set to $5 \mathrm{MPa}$ but not greater than $c / \tan \bullet$. From Fig.9a, the internal friction angle parameter affects the peak axial stress on the steel tube. On the other hand, the effect of the internal friction angle on the hoop stress was found to be negligible (see Fig.9b). As the internal friction angle value increases, the peak axial stress on the steel tube increases but the corresponding axial strain decreases. Moreover, the growth on the axial stress as the axial strain increases once the shear slip occurs was found to be higher as the internal friction angle increases.

Fig. 10a and Fig.10b show the comparison of the axial and hoop stresses distribution acting on the tube between the experimental test and numerical analysis with varying cohesive shear strength values, respectively. The internal friction angle value is set to $45 \mathrm{MPa}$ and the initial bond tensile strength is set to $5 \mathrm{MPa}$ but not greater than $c / \tan \bullet$. As shown in Fig.10a, the cohesive shear strength influenced the axial stress on the steel tube. The change in axial stress due to varying values of the cohesive shear strength was found to be shifting the curve (See Fig.10a) and the growth rate of the axial stress as the axial load increases was only barely affected. Higher cohesive shear strength also increases the peak axial stress acting on the tube, as well as shifting all the curve before the steel tube yields.

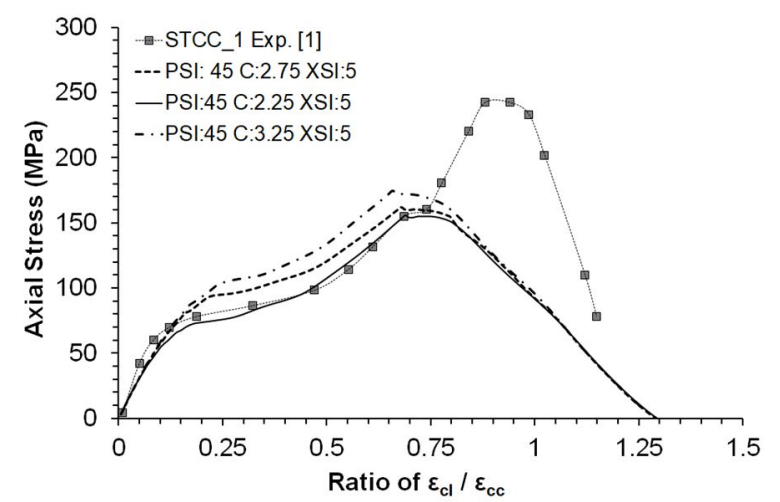

(a) Axial stress on the steel tube vs ratio of $\varepsilon_{\mathrm{cl}} / \varepsilon_{\mathrm{cc}}$

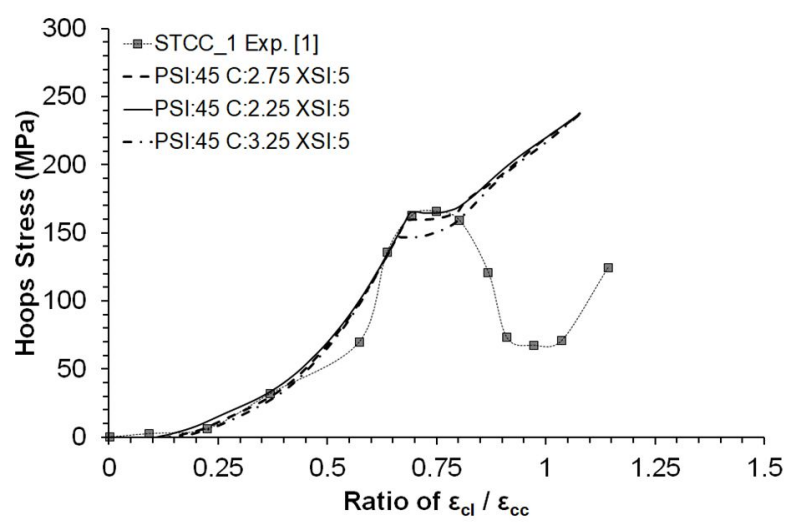

(b) Hoop stress on the steel tube vs ratio of $\varepsilon_{\mathrm{cl}} / \varepsilon_{\mathrm{cc}}$

Fig. 10 Stresses behavior on the steel tube with varying cohesive shear strength values

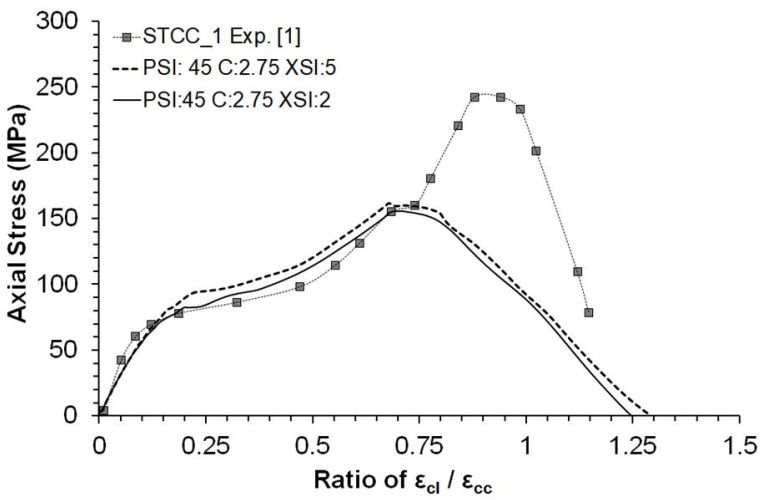

(a) Axial stress on the steel tube vs ratio of $\varepsilon_{\mathrm{cl}} / \varepsilon_{\mathrm{cc}}$

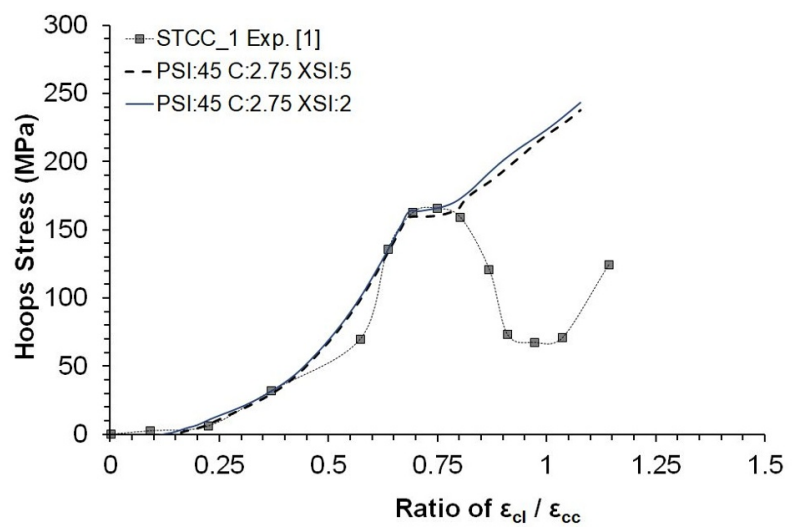

(b) Hoop stress on the steel tube vs ratio of $\varepsilon_{\mathrm{cl}} / \varepsilon_{\mathrm{cc}}$

Fig. 11 Stresses behavior on the steel tube with varying bond tensile strength values

Fig.11a and Fig.11b show the comparison of the axial and hoop stresses distribution acting on the tube between the experimental test and numerical analysis with varying initial bond tensile strength values, respectively. As shown in both Fig.11a and Fig.11b, the effect of this initial bond tensile strength was found to be negligible. However, a slight increase in the axial stress was observed when higher initial tensile bond strength was used.

From Fig.9, Fig.10, Fig.11, it was found that the axial peak stress acting on the steel tube was lower than the test result. In contrast with the hoop stress results where it was found to be higher than the test results. This author thinks this kind of behavior is an anomaly. Essentially, when the steel tube yields, the hoop stress should be always increasing and not decreasing. This can be well understood as when the steel yields, the ability of the steel tube to carry axial load would be reduced (as seen from the numerical results) and the axial load will be carried out by the concrete. At this stage, the concrete cracks formation become more evident and the formation of shear band could take places. This formation of shear band will trigger large lateral deformation in concrete which push the steel tube outward. This mechanism will increase the confining pressure on the concrete core and in turn the hoop stress in the steel tube will increase significantly as shown in Fig.9, Fig.10, Fig.11. This anomaly can also be caused by measurement error or due non-uniform localization in concrete. Nevertheless, the predicted axial load versus deformation curve as shown in Fig.3 was excellent. 


\section{Conclusions}

This paper presented a detailed analysis of a steel tube confined concrete (STCC) tested by [1] which includes detailed stress analysis, as well as sensitivity analysis of the constitutive model at the interface element. 3DNLFEA package [4-6] was used to predict the response of the selected STCC specimen. From the comparison, it was found out that the analysis results using 3D-NLFEA were in close agreement with the test results. The axial stressstrain curve was well predicted. This showed that the concrete constitutive model was sufficiently sensitive enough to model confinement of the STCC specimen.

To simulate the interaction between concrete and the steel tube, zero thickness element with Mohr-Coulomb failure surface was used. Detailed sensitivity analysis on the parameter used to define the interaction at the interface was presented. Some important conclusion from the observation between numerical and test results are as follows:

1. From the trial and error analysis to obtain the best fit of the stresses acting on the steel tube, the parameter for the interface element constitutive model is set to 2.75 $\mathrm{MPa}$ for the cohesive shear strength, 45 degrees for the internal friction angle, and $5 \mathrm{MPa}$ for the uniaxial bond tensile strength.

2. The variation of axial stress on the steel tube was found to be affected by interface modeling between the concrete and the steel tube. The minimum axial stress was found near the disconnected region while the maximum axial stress was found at the mid-height for each steel tube. The opposite finding was true for the hoop stress. The minimum hoop stress was found at the mid-height section for each steel tube. The maximum hoop stress was found near the disconnected region.

3. From the sensitivity analysis, the internal friction angle affects the growth rate of the axial stress distribution while the cohesive shear strength affects the overall axial stress distribution by shifting the axial stress-strain curve. The effect of initial bond tensile strength between concrete and the steel tube was found to be negligible.

\section{References}

1. J. Liu, Y. Teng, Y. Zhang, X. Wang, and Y. F. Chen, Const. Build. Mats. . 177 366-377 (2018)

2. M. Tomii, Procs. Int. Spec. Conf. Concrete-Filled Steel Tubular Struc. 19-26, (1985)
3. A. Le Hoang and E. Fehling, J. Const. Steel Res. 136 238-255, (2017)

4. B. Piscesa, Modeling confined concrete using plasticity formulation, $\mathrm{PhD}$. Thesis, School of Civil and Environmental Engineering, The University of New South Wales, Sydney, Australia,(2018)

5. B. Piscesa, M. M. Attard, D. Prasetya, and A. K. Samani, Engg. Struc. 196109336 (2019)

6. B. Piscesa, M. M. Attard, and A. K. Samani, Composite Struc. 194 478-493 (2018)

7. V. K. Papanikolaou and A. J. Kappos, Int. J. Solids Struc. 44 (21) 7021-7048 (2007)

8. A. Samani and M. Attard, Engg. Struc. 41 335-349, (2012) doi: http://dx.doi.org/10.1016/j.engstruct.2012.03.027.

9. A. K. Samani and M. M. Attard, ACI Struc. J. 111(16) (2014)

10. T. J. Hughes, The finite element method: linear static and dynamic finite element analysis. Courier Corporation, 2012.

11. B. Piscesa, M. Attard, A. Samani, and S. Tangaramvong, ACI Struc. J. 114(2) 361 (2017)

12. P. Menetrey and K. Willam, ACI Struc. J. 92(3) (1995)

13. B. Piscesa, M. M. Attard, and A. K. Samani, Composite Struc. 158 160-174 (2016)

14. B. Piscesa, M. M. Attard, and A. K. Samani, Procedia Engineering 171, 847-856, (2017)

15. B. Piscesa, The Third International Conference on Civil Engineering Research (ICCER), Surabaya, Indonesia, 1-2 August, (2017)

16. B. Piscesa, M. M. Attard, and A. K. Samani, XIV Int. Conf. Comp. Plast. Fund. Apps (COMPLAS) Barcelone, Spain, 5-7 September (2017)

17. H. Qi, L. Guo, J. Liu, D. Gan, and S. Zhang, ThinWalled Struc. 49 (9) 1141-1150 (2011)

18. R. E. Goodman, R. L. Taylor, and T. L. Brekke, J. Soil Mech. Found Div (1968)

19. M. Ortiz and J. Simo, Int. J. Num. Meth. Engg. 23(3) 353-366 (1986)

20. R. Lawther, Int. J Num. Meth. Engg. 15(8) 11491159 (1980)

21. SALOME - The Open Source Integration Platform for Numerical Simulation. http:/www.salomeplatform.org/. (2017). [Online]. Available: http://www.salome-platform.org/ 